\title{
Ethanol Affects Differentiation-Related Pathways and Suppresses Wnt Signaling Protein Expression in Human Neural Stem Cells
}

\author{
Sharada D. Vangipuram and William D. Lyman
}

\begin{abstract}
Background: Prenatal exposure of the fetus to ethanol (EtOH) can be teratogenic. We previously showed that EtOH alters the cell fate of human neural stem cells (NSC). As Wnt signaling plays an important role in fetal brain development, we hypothesized that EtOH suppresses Wnt signaling protein expression in differentiating NSC and thereby contributes to fetal alcohol spectrum disorder.

Methods: NSC isolated from fetal human brains were cultured in mitogenic media to induce neurospheres, which were dissociated into single-cell suspensions and used for all experiments. Equal numbers of NSC were cultured on lysine/laminin-coated plates for 96 hours in differentiating media containing 0,20 , or $100 \mathrm{mM} \mathrm{EtOH}$. Total mRNA was isolated from samples containing 0 or $100 \mathrm{mM} \mathrm{EtOH}$ and changes in expression of 263 genes associated with neurogenesis and NSC differentiation were determined by Oligo GEArray technology. The biological impact of gene changes was estimated using a systems biology approach with pathway express software and KEGG database. Based on the pathways identified, expression of Wnt proteins (Wnt3a and Wnt5a), Wnt-receptor complex proteins (p-LRP6, LRP6, DVL2, and DVL3), Wnt antagonist Naked-2 (NKD-2), and downstream Wnt proteins ( $\beta$-catenin, Tyr-p-GSK3 $\beta$, Ser-p-GSK3 $\beta$ ) were analyzed by Western blot.

Results: Of the 263 genes examined, the expressions of 22 genes in differentiating NSC were either upwardly or downwardly affected by EtOH. These genes are associated with 5 pathways/cellular processes: axon guidance; hedgehog signaling; TGF- $\beta$ signaling; cell adhesion molecules; and Wnt signaling. When compared to controls, EtOH, at both 20 and $100 \mathrm{mM}$ concentrations, suppressed the expression of Wnt3a and Wnt5a, receptor complex proteins p-LRP6, LRP6 and DVL2, and cytoplasmic proteins Ser-p-GSK3 $\beta$ and $\beta$-catenin. Expression of NKD-2 and DVL3 remained unchanged and the expression of active Tyr-p-GSK3 $\beta$ increased significantly.

Conclusions: EtOH can significantly alter neural differentiation pathway-related gene expression and suppress Wnt signaling proteins in differentiating human NSC.
\end{abstract}

Key Words: Fetal Brain, Signaling Pathways, Ethanol.

E

THANOL ing in a spectrum of deficiencies known as fetal alcohol spectrum disorder (FASD). Anomalies of FASD include craniofacial abnormalities and mental retardation in fetal alcohol syndrome the most severe form of FASD, whereas milder forms are characterized by behavioral and cognitive deficiencies such as attention deficit hyperactivity and developmental delay (Jones, 2011; Jones and Smith, 1973; Jones

From the Children's Research Center of Michigan, The Carman and Ann Adams Department of Pediatrics (SDV, WDL), Wayne State University School of Medicine, Detroit, Michigan; and Children's Hospital of Michigan, Detroit, Michigan.

Received for publication May 5, 2011; accepted September 22, 2011.

Reprint requests: Sharada Vangipuram, PhD, Children's Hospital of Michigan, 3901 Beaubien Street, 3N73, Detroit, MI 48201; Tel.: 313-966-2846; Fax: 313-745-0282; E-mail: svangipuram@med.wayne.edu Copyright (c) 2011 by the Research Society on Alcoholism.

DOI: 10.1111/j.1530-0277.2011.01682.x et al., 1974a,b; Kodituwakku, 2007; Kodituwakku et al., 2001; Mattson and Riley, 1998; Mattson et al., 1996).

Several mechanisms have been suggested as part of action of EtOH on the developing fetus as reviewed by Goodlett and colleagues $(2001,2005)$. These include disruption of cellular energy mechanisms such as alterations in glucose and DNA metabolism (Hu et al., 1995; Singh et al., 1993, 1994; Snyder and Singh, 1989; Snyder et al., 1992a,b), changes in cell-cell interactions and adhesion molecules (Bearer et al., 1999; Luo and Miller, 1999; Miñana et al., 1998, 2000; Ramanathan et al., 1996; Tang et al., 2006; Vangipuram et al., 2008) and alterations in growth factor and other signaling pathways (Alfonso-Loeches and Guerri, 2011; Hicks and Miller, 2011; Lindsley et al., 2011; de la Monte et al., 2011). Recently, neural stem cells (NSC) and progenitor cells have been the subjects of studies on EtOH neurotoxicity (Anthony et al., 2008; Camarillo and Miranda, 2008; Sathyan et al., 2007; Singh et al., 2009; Vangipuram and Lyman, 2010; Vangipuram et al., 2008; Zhou et al., 2011). We have previously 
shown that EtOH alters the cell fate and cell adhesion molecule (CAM) expression in human fetal brain derived NSC without increasing apoptosis (Vangipuram and Lyman, 2010; Vangipuram et al., 2008). Considering the number of possible mechanisms that could be involved in such an effect, we conducted an Oligo GEArray Microarray analysis to determine the differences in transcript levels between control and EtOH-treated human fetal brain derived NSC. For this study, we used a microarray that profiled the expression of 263 genes related to regulation of key neurogenesis processes such as regulators of cell proliferation and differentiation, synaptic transmission, synaptogenesis, and other key cellular functions.

Wnt signaling pathway plays an important role in embryogenesis and neurogenesis (Castelo-Branco and Arenas, 2006; Cerpa et al., 2009; Freese et al., 2010; Hur and Zhou, 2010; Smalley and Dale, 1999; Toledo et al., 2008). Wnts are shown to be essential at various stages of neural development including stem cell proliferation and maintenance of progenitor pool as well as in differentiation and lineage determination. Wnts are also known to be involved in cell migration, axon guidance, and neurite outgrowth as reviewed by Ille and Sommer (2005). Glycogen synthase kinase $\beta$ (GSK3 $\beta$ ), a key component of the Wnt signaling pathway has been shown to be involved in EtOH-induced neurotoxicity (Liu et al., 2009; Luo, 2009). Based on our Oligo GEArray analysis and on the existing data on the possible role of GSK $3 \beta$ in EtOH-induced neurotoxicity, we hypothesized that EtOH suppresses Wnt signaling pathway protein expression in fetal human brain derived NSC under differentiating conditions.

Cell surface markers CD133/prominin and nestin expression has been used to define NSC by several groups including ours (Hockfield and McKay, 1985; Lendahl et al., 1990; Tateno et al., 2004; Uchida et al., 2000; Vangipuram et al., 2008). To test our hypothesis we utilized CD133/nestin expression to select NSC from second trimester fetal human brain. Data obtained as a part of this study show that EtOH significantly suppresses endogenous levels of Wnt3a and Wnt5a and related receptor complex and cytoplasmic Wnt pathway proteins. As expected, EtOH increased Tyr phosphorylation of GSK $3 \beta$, which promotes degradation of $\beta$-catenin, a key downstream Wnt signaling pathway protein.

\section{MATERIALS AND METHODS}

\section{Isolation of Neural Progenitor Cells}

$\mathrm{CD} 133+/$ nestin + NSC were isolated from fetal human brain tissue (14 to 17 weeks of gestation) obtained from the Albert Einstein College of Medicine, Bronx, NY as previously described (Vangipuram and Lyman, 2010; Vangipuram et al., 2008). This study is part of an on-going research protocol approved by the human investigation committee, Wayne State University. Fetal brain tissue was obtained from voluntary terminations of normal pregnancies and the fetuses were not known to have been exposed to alcohol or tobacco. The tissue was washed with Hank's balanced salt solution and cleared of meninges. The tissue was diced and triturated and a singlecell suspension was obtained in serum-free complete Neurocult ${ }^{\mathrm{R}}$ NS-A proliferation medium containing Neurocult NS-A Basal medium (human), Neurocult NS-A proliferation supplements (STEMCELL Technologies, Vancouver, BC, Canada), $20 \mathrm{ng} / \mathrm{ml}$ each of hEGF and h-bFGF (Peprotech Inc., Rocky Hill, NJ), and $2 \mu \mathrm{g} / \mathrm{ml}$ of heparin. CD133 + cells (NSC) were positively selected from the cell suspension using anti-CD133 labeled magnetic microbeads from the MACS cell isolation kit (Miltenyi Biotechnologies, Auburn, CA). The purity of the isolated cell population was estimated by flow cytometry using anti-nestin antibody (R\&D Systems, Minneapolis, MN) and anti-CD 133 antibody (Miltenyi Biotechnologies). Isolated NSC were propagated as neurospheres in 6-well tissue culture plates at a density of 10 to $12 \times 10^{\mathbf{3}}$ cells per well.

\section{Immunophenotyping}

Isolated NSC were stained for CD133 and nestin expression as previously described (Barami et al., 2001; Vangipuram et al., 2008). Briefly, the cells were incubated with PE or FITC conjugated primary antibodies (anti-CD133 [Miltenyi Biotechnologies], or anti-nestin [R\&D systems]), in the dark for 20 minutes at room temperature and fixed with Coulter fixative. A 2 color analysis was performed using a Coulter XL Flow Cytometer (Coulter Corp, Miami, FL) gated on the viable cell population as inferred from forward and side scatter analyses. For cytoplasmic staining of nestin, the protocol described by Groeneveld and colleagues (1996) was slightly modified. Briefly, the cell suspensions were first fixed then permeabilized using Caltag's FIX and PERM kit (Caltag Labs, Burlingame, CA) according to manufacturer recommendations. Cells were incubated with isotype matched controls for all samples.

\section{EtOH Exposure}

NSC were isolated from 3 different fetal brain samples and all experiments were conducted separately for each brain sample. Neurospheres generated from CD133 + NSC were dissociated, characterized for CD133 and nestin expression, and used for EtOH exposure. A total of 10 to $12 \times 10^{3}$ cells were cultured on lysine/laminin-coated tissue culture plates in differentiation medium containing Neurocult NS-A Basal medium (human), Neurocult NS-A differentiation supplements (STEMCELL Technologies) with 0, 20, or $100 \mathrm{mM}$ EtOH. Tissue culture plates were placed in saturated EtOH chambers to mitigate evaporation of EtOH from the culture media (Rodríguez et al., 1992). EtOH containing media were prepared freshly before use with $200^{\circ}$ absolute $\mathrm{EtOH}$. The EtOH dose range was selected and confirmed to be equivalent to the concentrations of alcohol in the blood of social drinkers to chronic alcoholics (Adachi et al., 1991; Perper et al., 1986) and has been used previously by others in relevant cell culture experiments (Tateno et al., 2004, 2005). The cells were exposed to $\mathrm{EtOH}$ for 96 hours in a humidified atmosphere containing $5 \% \mathrm{CO}_{2}$ at $37^{\circ} \mathrm{C}$.

\section{Total RNA Isolation}

After 96 hours, total RNA was extracted from control and $100 \mathrm{mM}$ EtOH-treated NSC using RNeasy mini kit (Qiagen Inc. Valencia, CA) as per the kit manufacturer's protocol. The quality and quantity of RNA was assessed using an Agilent Bioanalyzer (Agilent Technologies, Santa Clara, CA). RNA with RNA Integrity Number $($ RIN) $>9$ was used for Oligo GEArray DNA Microarray analysis using human neurogenesis and NSC array (SuperArray Biosciences, Frederick, MD).

\section{Oligo GEArray DNA Microarray Analysis}

Human neurogenesis and NSC Oligo GEArray DNA Microarray was used to determine differential transcript levels between control and $100 \mathrm{mM}$ EtOH-treated samples $(n=3)$. The microarray profiled the expression of 263 genes related to regulation of key 
neurogenesis processes. Standard Hyb tube protocol was followed for the analysis as per the kit manufacturer's directions. Briefly, $3 \mu \mathrm{g}$ of high quality total RNA (RIN > 9) was used to synthesize complementary C-DNA. True labeling-AMP 2.0 Oligo GEArray starter kit was used for c-RNA synthesis, amplification and biotinylation. C-RNA was purified using SuperArray ArrayGrade ${ }^{\mathrm{TM}}$ cRNA Cleanup Kit. A Nanodrop 1000 spectrophotometer (Thermo Scientific Inc., Rockford, IL) was used to assess the c-RNA yield and quality.

\section{Oligo GEArray Hybridization and Detection}

Oligo GEArray membranes were hybridized with $4 \mu \mathrm{g}$ of biotinylated C-RNA from control and EtOH-treated samples $(n=3)$ as per kit manufacturer's protocol. Briefly, the membranes were prehybridized in hybridization solution for 2 hours at $60^{\circ} \mathrm{C}$ with continuous, but slow agitation, followed by hybridization with C-RNA at $60^{\circ} \mathrm{C}$, overnight with gentle agitation. The membranes were then washed and the signals detected using the chemiluminescent detection kit (SuperArray Biosciences) and digitized using Carestream CCD camera system (Carestream Health Inc., New Haven, CT). Fold change $(1$-fold $=100 \%)$ in the expression of genes from EtOHtreated and control samples were compared using integrated GEArray expression analysis software. Oligo GEArray ${ }^{\circledR}$ Human Neurogenesis and Neural Stem Cell Microarray from SuperArray Biosciences contained 263 genes which included positive and negative regulators of cell proliferation, negative regulators of cell cycle, cell cycle arrest genes, regulators of cell differentiation, synaptic transmission, synaptogenesis, apoptosis, and cell adhesion. Further, the array also included genes involved in neurogenesis such as molecules of notch signaling, Wnt receptor and $\mathrm{G}$ protein-coupled receptor pathways. Fold change $(1$-fold $=100 \%$ ) in the expression of these genes from EtOH-treated and control samples were compared using integrated GEArray expression analysis software. All data sets were corrected using the lowest density reading of a spot on the array for background subtraction. After background subtraction, interquartile value was used for normalization. The interquaritle normalization option normalizes each spot brightness to the mean intensity value of all the spots in the middle half $(50 \%)$ of the range that remains after ignoring the most and least intense quarter $(25 \%)$ of the entire data set. Only genes that showed up or down-regulation of at least 1.5 -fold or more were considered to have been altered by EtOH.

\section{Pathway Analysis}

The potential biological impact of changes in gene expression was estimated using a systems biology approach that employs an impact analysis method of pathway express software. Pathway express and OntoExpress analysis software (Draghici et al., 2003; Khatri et al., 2005) was utilized to estimate the significance of gene changes in relation to biological pathways. Using this method, an impact factor is calculated for each pathway by incorporating multiple factors such as the normalized fold change of differentially expressed genes, the statistical significance of the set of pathway genes, and the topology of the signaling pathway (from KEGG database). Pathways which showed an impact factor higher than 5 along with a $p$-value $\leq 0.05$ were considered to be significantly altered.

\section{Western Blot Analysis}

Western blot analysis was performed on control and EtOH-treated samples as previously described (Vangipuram and Lyman, 2010). CD133 + NSC differentiating in laminin/lysine-coated 6 well plates were lysed with NP-40 lysis buffer containing $0.15 \mathrm{M} \mathrm{NaCl} ; 1 \mathrm{mM}$ EGTA; $1 \mathrm{mg} / \mathrm{ml} \mathrm{BSA;} 10 \mathrm{mM}$ Tris; 1\% NP-40; $0.2 \mathrm{mM}$ phenylmethylsulfonyl fluoride; $5 \mathrm{mg} / \mathrm{ml}$ aprotinin, leupeptin, and pepstatin, pH 7.4 after washing with ice-cold PBS. Unlysed cells were pelleted by centrifuging at $13,000 \times g$ for 15 minutes at $4^{\circ} \mathrm{C}$ in Beckman microcentrifuge (Beckman Coulter, Fullerton, CA). The protein concentrations of the lysates were determined using the Pierce protein estimation kit (Thermo Fisher scientific Inc.). The expression of Wnt proteins (Wnt3a and Wnt5a), Wnt-receptor complex proteins (p-LRP6, LRP6, DVL2, and DVL3), Wnt antagonist Naked-2 (NKD-2), and downstream Wnt proteins ( $\beta$-catenin, Tyr-p-GSK3 $\beta$, Ser-p-GSK $3 \beta$ ) from the Wnt canonical pathway were analyzed by Western blot. Briefly, 25 to $30 \mu \mathrm{g} /$ lane of protein lysates of all samples was loaded on $10 \%$ sodium dodecyl sulfate polyacrylamide gel electrophoresis gel, separated by gel electrophoresis, and then transferred to PVDF membranes. The membranes were washed with PBS-T and nonspecific binding was blocked with 5\% nonfat dry milk in PBS-T for 1 hour with shaking. The membranes were then incubated with primary antibodies (Cell Signaling Technology, Danvers, MA) overnight with shaking at $4^{\circ} \mathrm{C}$. Subsequent to washing, the membranes were incubated with secondary goat anti-rabbit peroxidase-conjugated antibody for 1 hour at $25^{\circ} \mathrm{C}$. The membranes were then developed and visualized with the Pierce ECL Western blotting substrate (Pierce, Rockford, IL) followed by apposition of the membranes with autoradiographic Kodak X-OMAT AR film (Rochester, NY). The protein expression was quantified by digitizing the ECL signals using Carestream molecular imaging software 5.0. The bands corresponding to the expected molecular weight were analyzed for each of the proteins where more than 1 band was seen (Tyr-p-GSK $3 \beta$ - 47 kDa, SER-p-GSK3 $\beta$ - 46 kDa, Wnt3a$42 \mathrm{kDa}, \beta$-actin $-45 \mathrm{kDa}$, and NKD-2-59 kDa). In all cases, the darkest band corresponded to the expected molecular weight.

\section{Statistical Analysis}

To examine mean differences in band densities of various proteins a parametric analysis of variance (ANOVA) procedure was employed. Assumptions of normality and/or homogeneity of variance were checked and verified. Normality was checked using stem and leaf plots and histograms. Homogeneity of variance was formally checked using Levene's statistic. Post hoc tests were conducted using Bonferroni's correction to balance multiple tests of hypotheses (pair-wise comparisons) and Type I error. SPSS Version 19.0 (IBM Inc., Chicago, IL) was used to perform all statistical procedures. Statistically significant differences were considered achieved with a $p$-value $<0.05$.

\section{RESULTS}

\section{Generation of Neurospheres from NSC Isolated from Second Trimester Fetal Human Brain}

NSC were isolated from second trimester fetal human brain by positive immuno-selection. CD 133 and nestin expression was used to confirm the differentiation state of the cells (Fig. 1). Neurospheres were generated from these cells in serum-free mitogenic media in the presence of hEGF and bFGF as previously described (Vangipuram and Lyman, 2010; Vangipuram et al., 2008) and dissociated for experiments.

\section{Oligo GEArray Analysis of Control and EtOH-Treated} NSC

Oligo GEArray ${ }^{\circledR}$ Human Neurogenesis and Neural Stem Cell Microarray containing 263 genes related to neurogenesis and NSC differentiation including 12 housekeeping genes, 


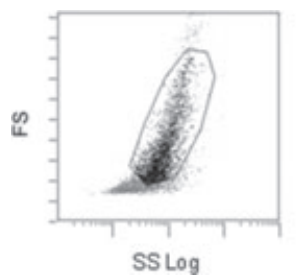

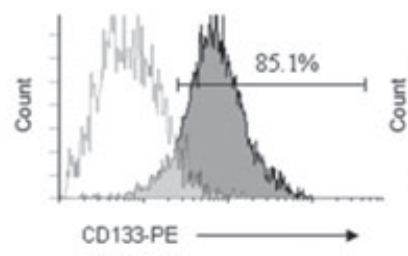

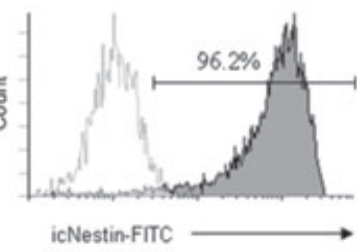

Fig. 1. Two color analysis using a Coulter XL Flow Cytometer on viable neural stem cells (NSC) population showing percentage of cells expressing CD133 and nestin.

was used to study the effect of EtOH on NSC. The transcript signals were detected on the membranes by chemiluminiscent detection system and visualized on Carestream CCD camera. Using integrated GEArray expression analysis software, 22 genes were identified to be altered by at least 1.5 -fold compared with controls. Of these, 6 genes were up-regulated and 16 genes were down-regulated (Table 1). Of the 263 genes on the array, 138 genes were absent in the samples (Table S1).

\section{Pathway Express Analysis}

The pathway express and OntoExpress analysis software was used to assign altered genes from the Oligo GEArray results to specific biological pathways/cellular processes with highest impact as described (Draghici et al., 2003; Khatri et al., 2005). Five pathways/cellular processes were identified to have an impact factor greater than 5 and a $p$-value $<0.05$, namely, axon guidance, hedgehog signaling, TGF- $\beta$ signaling, CAMs, and Wnt signaling (Table 2). Of the pathways identified, Wnt signaling pathway was chosen for in-depth study due to the role played by Wnt signaling in neural development and neurogenesis (Cadigan and Nusse, 1997; Toledo et al., 2008) and in EtOH-induced neurotoxicity (Liu et al., 2009; Luo, 2009).

\section{Western Blot Analysis of Wnt Signaling Pathway Proteins}

Endogenous levels of Wnt proteins Wnt3a and Wnt5a were first estimated by Western blot analysis and band intensities estimated by densitometry. Expressions levels of both Wnts studied were significantly suppressed in differentiating NSC with exposure to both 20 and $100 \mathrm{mM}$ concentrations of

Table 1. List of Genes Altered by Ethanol in Differentiating Neural Stem Cells Determined by Oligo GEArray Analysis

\begin{tabular}{|c|c|c|c|}
\hline Gene symbol & Gene name & $\begin{array}{l}\text { Fold expressed } \\
\text { relative to control }\end{array}$ & Function in fetal brain development \\
\hline HDAC4 & Histone deacetylase4 & 1.78 & Involved in TGF- $\beta$ induced differentiation \\
\hline HEY1 & $\begin{array}{l}\text { Hairy/enhancer-of-split related with } \\
\text { YRPW motif protein } 1\end{array}$ & 1.54 & Implicated in neurogenesis and somitogenesis \\
\hline MDK & Midkine-neurite growth promoting factor 2 & 1.84 & Cell proliferation, cell migration, angiogenesis, and fibrinolysis \\
\hline PBX4 & Pre-B cell leukemia homobox-4 & 1.99 & Transcriptipn factor involved in translocations \\
\hline $\mathrm{PCDH} 1$ & Protocadherin & 3.14 & Involved in neural adhesion and development \\
\hline SPOCK1 & Testican 1 & 3.10 & Unknown-possible protease inhibition \\
\hline $\mathrm{ACHE}$ & Acetylcholinesterase & 0.31 & Apoptosis related \\
\hline APAF 1 & Apoptotic protease activating factor 1 & 0.63 & Part of apoptosis regulatory network \\
\hline APBA1 & Adapter protein $\times 11$ alpha, & 0.57 & Essential component of synaptic vescicles \\
\hline APBB2 & $\begin{array}{l}\text { Amyloid beta A4 precursor protein-binding } \\
\text { family B member } 2\end{array}$ & 0.47 & Involved in signal transduction \\
\hline APLP1 & amyloid beta (A4) precursor-like protein & 0.32 & Role in postsynaptic function \\
\hline EP300 & E1A binding protein p300 & 0.61 & Important role in cell proliferation and differentiation \\
\hline MT3 & Metallothionein-3 & 0.62 & Survival and neurite formation of cortical neurons \\
\hline NCKAP1 & NCK-associated protein 1 & 0.52 & Membrane associated protein \\
\hline NDP & Norrie disease (pseudoglioma) & 0.64 & Mutations in Norrie Disease \\
\hline NRCAM & Neuronal cell adhesion molecule & 0.64 & Involved in neuron-neuron adhesion and directional growth \\
\hline POU6F1 & POU class 6 homeobox & 0.65 & \\
\hline PTN & Pleotrophin & 0.66 & Neurite growth promoting factor \\
\hline ROBO1 & Roundabout homolog 1 & 0.55 & Axon guidance receptor and cell adhesion receptor \\
\hline SOD1 & Superoxide dismutase 1 & 0.63 & Neutralizes supercharged oxygen molecules \\
\hline SOX3 & SRY-related HMG-box & 0.64 & Cell fate determination \\
\hline TFAP2B & Transcription factor AP-2 beta & 0.52 & $\begin{array}{l}\text { Stimulates cell proliferation and suppresses } \\
\text { terminal differentiation }\end{array}$ \\
\hline
\end{tabular}

References for gene functions are available in Data S1. Values showed in bold represent up-regulated genes. 
Table 2. Pathways Significantly Impacted by Ethanol in Differentiating Neural Stem Cells Determined by Pathway Analysis Software

\begin{tabular}{|c|c|c|c|c|c|c|c|}
\hline \multirow[b]{2}{*}{ Pathway } & \multirow{2}{*}{$\begin{array}{l}\text { Genes } \\
\text { involved }\end{array}$} & \multicolumn{3}{|c|}{ Impact factor } & \multicolumn{3}{|c|}{$p$-Value } \\
\hline & & FB 1 & FB 2 & FB 3 & FB 1 & FB 2 & FB 3 \\
\hline Axon guidance & $\begin{array}{l}\text { ROBO1 } \\
\text { NRCAM } \\
\text { PTN } \\
\text { SOD1 }\end{array}$ & 15.99 & 10.44 & 6.57 & 5.35E-07 & 1.2E-04 & 0.010 \\
\hline Hedgehog signaling & $\begin{array}{l}\text { HDAC4 } \\
\text { HEY1 } \\
\text { PBX4 } \\
\text { ROBO1 } \\
\text { PTN }\end{array}$ & 5.48 & 9.12 & 7.07 & 0.0078 & 1.9E-04 & 8.4E-04 \\
\hline TGF- $\beta$ signaling & $\begin{array}{l}\text { HDAC4 } \\
\text { SOX3 } \\
\text { NRCAM } \\
\text { MT3 } \\
\text { EP300 }\end{array}$ & 4.99 & 11.67 & 3.48 & 0.017 & 2.3E-05 & 0.07 \\
\hline Cell adhesion molecules & $\begin{array}{l}\text { PCDH1 } \\
\text { NCKP1 } \\
\text { NRCAM } \\
\text { HDAC4 }\end{array}$ & 8.1 & 10.44 & 3.01 & 0.038 & 0.028 & 0.01 \\
\hline Wnt signaling & $\begin{array}{l}\text { HEY1 } \\
\text { PBX4 } \\
\text { PCDH1 } \\
\text { ACHE } \\
\text { EP300 }\end{array}$ & 9.45 & 10.12 & 3.84 & 7.88E-05 & 2.1E-04 & 0.012 \\
\hline
\end{tabular}

EtOH (Fig. 2). Subsequently, expression of Wnt receptor complex proteins, phosphorylated and total LRP6, DVL2, DVL3, and Wnt antagonist NKD-2 were studied. Although there was no significant change in the expression of NKD-2 and DVL3, expression of phosphorylated LRP6 and DVL2 was significantly suppressed by 20 and $100 \mathrm{mM}$ EtOH and total LRP6 was significantly suppressed by $100 \mathrm{mM}$ EtOH (Fig. 3). Finally, expression of cytoplasmic Wnt proteins, $\beta$-catenin, and GSK3 $\beta$ were studied. As expected, EtOH significantly suppressed the expression levels of $\beta$-catenin and Ser phosphorylated and total GSK $3 \beta$. Expression of active Tyr phosphorylated GSK $3 \beta$ which phosphorylates cytoplasmic $\beta$-catenin leading to its ubiquitination and degradation, was significantly increased with EtOH exposure (Fig. 2).

\section{DISCUSSION}

The major finding of this study is that exposure of differentiating human NSC to EtOH significantly alters the levels of gene transcripts that could potentially impact 5 major cellular pathways/processes as computed by pathway express software analysis. These are: axon guidance, hedgehog signaling, TGF- $\beta$ signaling, CAMs, and Wnt signaling (Table 2). Further, this study also shows that the key components of the Wnt signaling pathway are suppressed by EtOH in a doserelated manner suggesting that Wnt signal suppression could be a significant part of the mechanism of action of EtOH on NSC.

CD133, a 5-trans-membrane glycoprotein (Miraglia et al., 1997) and nestin, have been used as markers to confirm the undifferentiated state of NSC and to isolate NSC from a heterogeneous population of cells by our group and others (Tamaki et al., 2002; Uchida et al., 2000; Vangipuram and Lyman, 2010; Vangipuram et al., 2008). In this study, we utilized the expression of CD133 to positively select NSC from second trimester fetal human brain and study the effects of EtOH on those cells while differentiating on laminin/lysine coated plates.

Although the teratogenic potential of EtOH has been known for more than 30 years (Jones et al., 1973, 1974a,b), neither the most vulnerable cell population in the developing brain nor the exact mechanism of action of $\mathrm{EtOH}$ on the developing fetus have been identified.

Several mechanisms have been proposed to explain the teratogenic action of EtOH. A number of groups, including ours, have suggested that EtOH alters CAM expression. Miñana and colleagues (2000) have shown that EtOH alters the pattern of NCAM expression during brain development, whereas Bearer and colleagues (1999) have suggested a possible L1-mediated inhibition of neurite outgrowth by EtOH. TGF- $\beta$ induced NCAM expression has been shown to be inhibited by EtOH (Luo and Miller, 1999). Alcohol induced oxidative stress leading to cell death and damage has been proposed as another possible mechanism of action (Guerri, 1998; Henderson et al., 1995; Kotch et al., 1995). Alterations to DNA metabolism (Dreosti et al., 1981; Pennington et al., 1983; Shibley and Pennington, 1997) has been suggested as yet another possible mechanism. Others include, changes in energy and glucose metabolism (Mann et al., 1975; Miller and Dow-Edwards, 1993; Vingan et al., 1986) and alterations in growth factor mediated pathways as shown by several groups including those of Jones, Guerri and others 
A

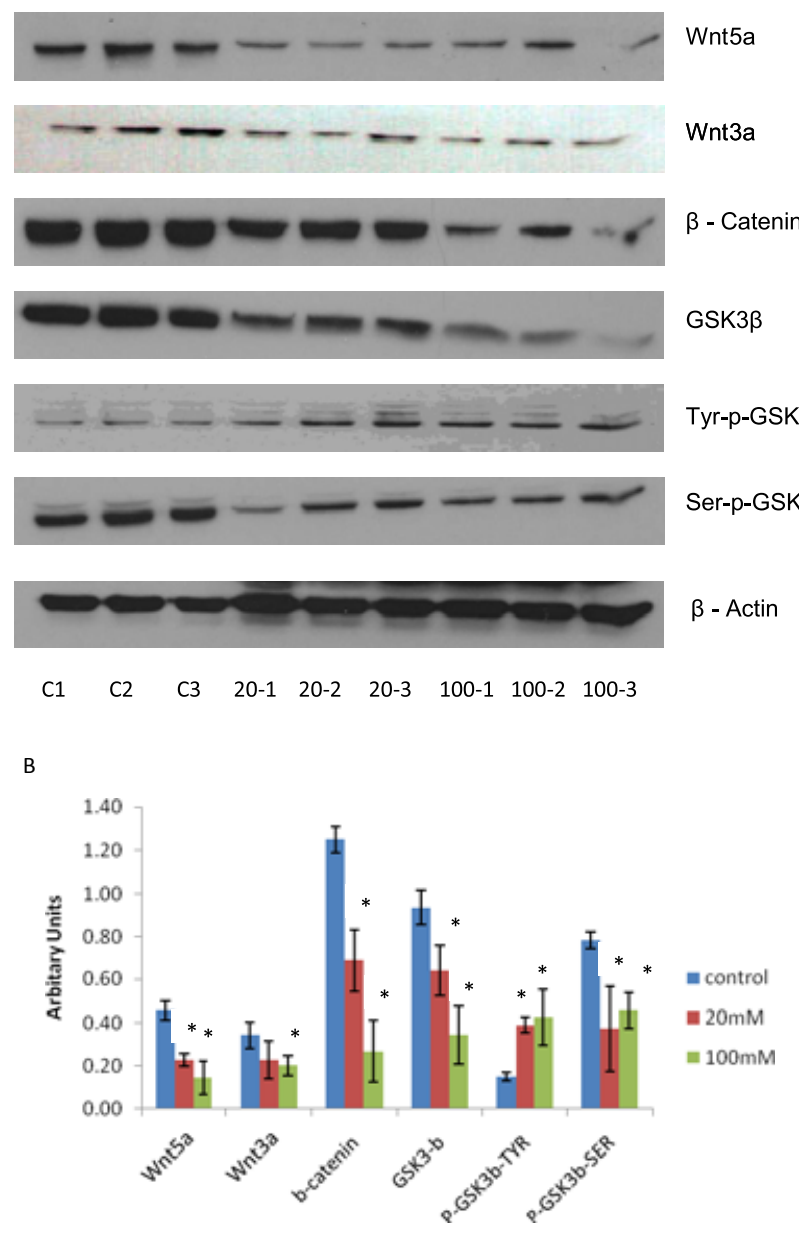

Fig. 2. (A) Representative Western blot analysis of Wnt signaling protein expression in differentiating neural stem cells (NSC) exposed to 0,20 , or $100 \mathrm{mM}$ ethanol (EtOH). C: Control NSC; 20: NSC exposed to $20 \mathrm{mM}$ EtOH for 96 hours; 100: NSC exposed to $100 \mathrm{mM}$ EtOH for 96 hours. (B) Band densitometry of Wnt signaling proteins: ratios of band intensities relative to $\beta$-actin expression $(n=3)$. Asterisks indicate a statistically significant difference in the mean densities compared with controls $\left({ }^{*} p<0.05\right)$.

(Alfonso-Loeches and Guerri, 2011; Hicks and Miller, 2011; Jones, 2011). Several studies over the past 2 decades have suggested that prenatal alcohol has a direct effect on progenitor and stem cell populations of the developing brain (Guerri et al., 1990; Miller, 1989; Miller and Nowakowski, 1991; Sathyan et al., 2007; Vangipuram and Lyman, 2010; Vangipuram et al., 2008). These studies taken together suggest that EtOH possibly alters multiple pathways simultaneously leading to the signs of FASD. Further, in the developing brain EtOH could also have independent and sometimes even opposing effect on the different cell types. Considering the crucial role played by NSC and their multipotency, as a first step we chose to use human CD133 + cells to study the effect of EtOH. Next, we chose to use an Oligo GEArray analysis method to screen for the changes in various differentiation and neurogenesis-related transcripts to identify possible pathways affected by EtOH in human NSC.
A

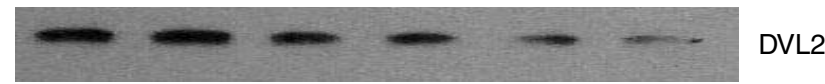

DVL2

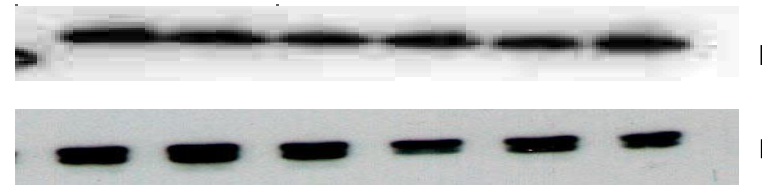

DVL3

NKD-2
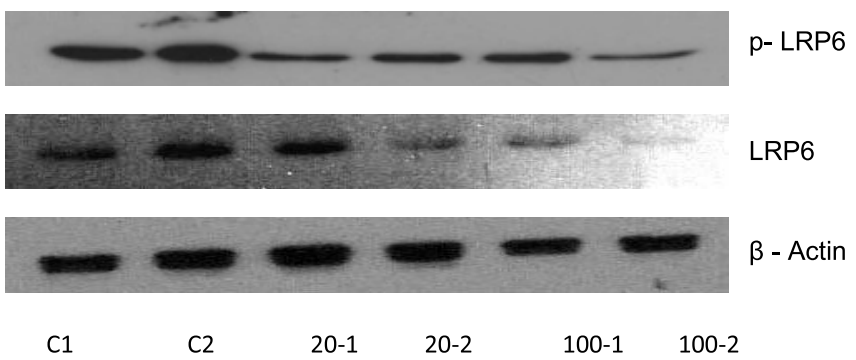

$\beta-$ Actin

B

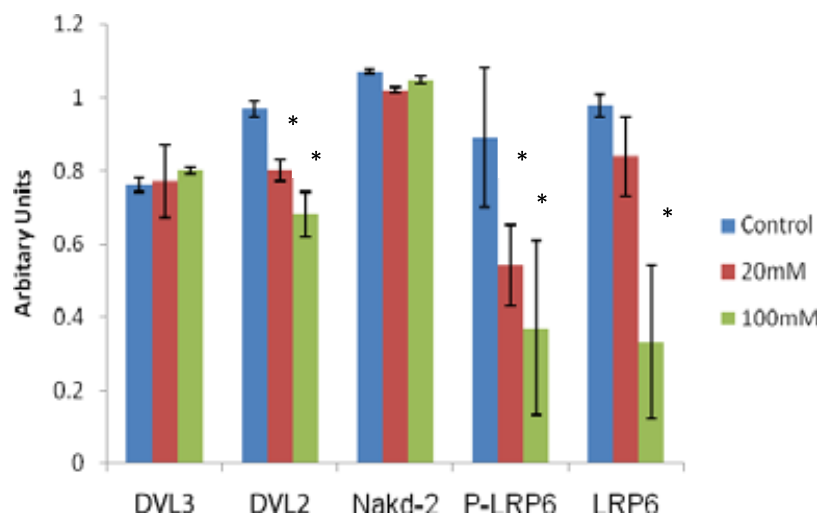

Fig. 3. (A) Representative Western blot analysis of Wnt receptor complex protein expression in differentiating neural stem cells (NSC) exposed to 0, 20, or $100 \mathrm{mM}$ ethanol (EtOH). C: Control NSC; 20: NSC exposed to $20 \mathrm{mM}$ EtOH for 96 hours; 100: NSC exposed to $100 \mathrm{mM} \mathrm{EtOH}$ for 96 hours. (B) Band densitometry of Wnt receptor complex proteins: ratios of band intensities relative to $\beta$-actin expression $(n=3)$. Asterisks indicate a statistically significant difference in the mean densities compared with controls $\left({ }^{*} p<0.05\right)$.

We exposed NSC to $100 \mathrm{mM}$ EtOH for 96 hours under differentiating conditions as has been done previously in cell culture experiments (Prock and Miranda, 2007; Tateno et al., 2005; Vangipuram and Lyman, 2010; Vangipuram et al., 2008). A lower $20 \mathrm{mM}$ dose of EtOH was also used in subsequent experiments to determine Wnt protein expression by Western blot.

Oligo GEArray Human Neurogenesis and Neural Stem Cell Microarrays have previously been used by other groups to study the changes in gene expressions in differentiating stem cells (Greco and Rameshwar, 2007). Our microarray data show that 22 genes were either up- or down-regulated by $\mathrm{EtOH}$ in differentiating NSC (Table 1) which were determined to have a high impact on 5 crucial pathways/cellular processes (Table 2). It is interesting that each of the 5 pathways/cellular processes affected by EtOH is independently essential for normal development of fetal brain. A similar 
observation has been made by Hashimoto-Torii and colleagues (2011) who have recently shown that multiple pathways are altered by alcohol exposure in fetal human cerebral cortex in vitro including the Wnt signaling and TGF- $\beta$ signaling pathways.

Axon Guidance. Axon guidance is an important stage in neuronal network formation. Several factors are involved in guidance of axons such as netrins, ephrins, slits, and semaphorins ( $\mathrm{Yu}$ and Bargmann, 2001). These cues are read by growth cone receptors, and subsequently the signal transduction pathways downstream of these receptors bring changes in cytoskeletal organization that determines the direction of growth. It has been suggested prenatal $\mathrm{EtOH}$ disrupts the outgrowth of axons and dendrites in the development of rat hippocampus. Furthermore, Lindsley et al. $(2003,2006)$ have shown that prenatal EtOH retards initial axon outgrowth, but accelerates subsequent axon growth suggesting that EtOH may disrupt the axonal response to guidance cues. In our study with human NSC, we find that EtOH significantly alters the axon guidance pathway. It is possible that these early effects of EtOH on NSC could be responsible for the subsequent disruption in the axonal guidance (Table 2).

Hedgehog Pathway. The hedgehog proteins play an important role in the vertebrate embryogenesis and fetal development. Of the 3 hedgehog morphogens, sonic hedgehog (Shh), Desert hedgehog (Dhh), and Indian hedgehog (Ihh), Shh is known to play an important role not only in ventral patterning of the neural tube but also in determining the dopaminergic and seratoninergic cell fates of neural plate (Charytoniuk et al., 2002). Several studies have shown that $\mathrm{EtOH}$ directly alters the Shh pathway in developing fetal brain in vivo. Ahlgren and colleagues (2002) have shown that $\mathrm{EtOH}$ induced cell death in neural crest cells is rescued by Shh in chick embryos. Other studies in mice have shown that fetal alcohol exposure impairs Shh signaling (Chrisman et al., 2004; Li et al., 2007; Loucks and Ahlgren, 2009; Yamada et al., 2005). Our microarray analysis showed that EtOH exposure to differentiating human NSC significantly disrupts Shh signaling (Table 2). It is possible that the early disruption of Shh pathway could lead to the neural crest cell death seen in FASD.

TGF- $\beta$ Signaling. The transforming growth family members include several cytokines such the TGF- $\beta$ s, activins, and bone morphogenetic proteins. Several functions have been attributed to the TGFs including, cell proliferation, differentiation, and migration. Yi and colleagues (2010) have shown that TGF- $\beta$ signaling specifies axons during brain development in mice in vivo and that TGF- $\beta$ receptors are expressed during development. Recently, Hicks and Miller (2011) have shown that EtOH-induced apoptosis in stem cells is mediated by both TGF- $\beta$ dependent and independent mechanisms. Kuhn and Sarkar (2008) have shown that EtOH induces apoptotic death of endorphin neurons in rat by a
TGF- $\beta$ dependent mechanism. A disruption of TGF- $\beta$ signaling is seen in our study with human NSC and $\mathrm{EtOH}$ which could be a part of the mechanism of action of $\mathrm{EtOH}$.

Cell Adhesion Molecules. CAMs are cell surface glycoproteins which play a vital role in several cellular processes including embryogenesis and fetal neural development. Several studies have shown the importance of CAMs in neural development and that alcohol affects the expression of several CAMs (Parashar et al., 2010; Sakata-Haga et al., 2003; Siegenthaler and Miller, 2004). We suggest based on our microarray study that the changes in CAMs begin to occur at the NSC level in human fetal brain exposed to EtOH. Although all the above pathways appear to be affected by $\mathrm{EtOH}$ in human NSC, an in-depth study of the various molecules in each pathway is warranted to elucidate the exact mechanism of action of EtOH. In this study, we chose to investigate the effects of EtOH on the Wnt signaling pathway proteins in differentiating human NSC.

Wnt Signaling Pathway. Several functions have been attributed to Wnt signaling in neuronal development as reviewed by Ille and Sommer (2005). Wnts are secreted palmitoylated glycoproteins, which besides playing a key role in progenitor and stem cell expansion and maintenance also play a major role in differentiation processes leading to lineage decisions and in migration, axon guidance, and neurite out growth. Several studies have implicated Wnt signaling in the normal fetal brain development and neurogenesis. McMahon and Bradley (1990) have shown that ablation of Wnt1 protein caused deficiencies in the mid-hind brain formation in mice, Lee and colleagues suggest that Wnt3a is crucial in the development of the hippocampus and Wnt $3,-3 a,-7 b$, and $-8 b$ participate in the normal development of forebrain (Lee et al., 2000; Toledo et al., 2008). Severe murine phenotypes were observed with ablation or overexpression of Wnt proteins in mice (van Amerongen and Berns, 2006). Haegele and colleagues (2003) have shown that inhibition of Wnt signaling proteins impaired the differentiation of stem cells. Singh and colleagues (2009) have shown involvement of Wnt proteins in the impaired neurogenesis seen in pups when pregnant rats were administered EtOH (Singh et al., 2009). Neznanova and colleagues (2009) have shown that EtOH increased GSK3 $\beta$ and AKT phosphorylation in the tissue from medial prefrontal cortex suggesting a role for the Wnt signaling pathway in the action of EtOH.

The Wnts bind to cell surface receptors activating signaling cascades that follow 3 major pathways: (i) the $\mathrm{Wnt} / b$-catenin pathway, the canonical Wnt signaling pathway, in which $\beta$ catenin is a crucial member, (ii) the Frizzled/planar cell polarity pathway, and (iii) the Ca2 + pathway (Kühl et al., 2000).

In the Wnt canonical pathway, secreted extra cellular Wnts bind to a 7 transmembrane FZ proteins and lipoprotein receptor proteins (LRP) to form a complex. The phosphorylation of LRPs leads to phosphorylation of Dsh proteins in the cytoplasm. Dsh proteins when activated by the Wnts inhibit 
GSK3 phosphorylation by forming an axin/GSK3 $\beta /$ APC complex. This complex when uninhibited promotes proteolytic degradation of $\beta$-catenin. In the presence of Wnt, axin/ GSK $3 \beta /$ APC complex is inhibited promoting a cytoplasmic pool of $\beta$-catenin which enters the nucleus to interact with TCF/LEF transcription factors to promote specific gene transcription. In our study, EtOH significantly suppressed the expression of 2 Wnt family proteins, Wnt3a and Wnt5a, both of which are involved in neurogenesis. Further, Wnt receptor complex proteins LRP6 and DVL2 were also significantly suppressed by EtOH in a dose-related manner. However, the Wnt antagonist NKD-2 and the receptor protein DVL3 were not affected by EtOH (Fig. 2). This suggests that action of EtOH is specific to only some of the pathway proteins. Next, we studied the expression of inactive Ser phosphorylated GSK $3 \beta$ and active Tyr phosphorylated GSK $3 \beta$. GSK $3 \beta$ is a multifunctional Ser-thr enzyme and plays a key role in several pathways including the Wnt signaling pathway. It plays an important role in the development of the central nervous system, regulating diverse early events, including neurogenesis, neuronal migration, cell adhesion, synapse formation, neuronal survival, and neurite outgrowth. GSK $3 \beta$ is particularly abundant in the developing nervous system and has been implicated in EtOHinduced neurotoxicity in vivo (Luo, 2009). In this study, we find that EtOH suppressed the Ser phosphorylation of GSK3 $\beta$ in both doses tested and simultaneously significantly increased Tyr phosphorylation leading to increased $\beta$-catenin phosphorylation (Fig. 3). Phosphorylated $\beta$-catenin undergoes immediate proteosomal degradation and ubiquitination. As expected, the levels unphosphorylated $\beta$-catenin were significantly suppressed by EtOH (Fig. 3). A similar reduction in $\beta$-catenin levels in EtOH exposed neural crest progenitors has recently been reported by Flentke and colleagues (2011) who have further shown that normalizing $\beta$-catenin levels prevents neural crest loss. Lange and colleagues (2011) suggest that small molecule GSK3 inhibitors increase neurogenesis of human neural progenitor cells. Recent studies show that lithium, a GSK $3 \beta$ inhibitor, protects against EtOH neurotoxicity (Luo, 2009). As we show that EtOH has a direct effect on the Ser/Tyr phosphorylation of GSK $3 \beta$ in human cells, in vivo studies to reverse FASD in animal models using small molecule GSK3 inhibitors could shed light on possible future therapies.

We infer from our current data, that EtOH significantly alters at least 5 major pathways/cellular processes involved in neuronal development in differentiating NSC. Further, EtOH suppresses Wnt signaling pathway proteins that are involved in specific gene transcription in brain development. These findings could be a significant step in elucidation of the mechanism of action of EtOH on the developing brain. Future in vivo and in vitro studies using GSK $3 \beta$ inhibitors could lead to possible therapeutic interventions.

\section{ACKNOWLEDGMENTS}

The authors thank Dr. Bradford Poulos for providing the fetal human brain tissue, Mr. Steven Buck for assistance with flow cytometry, and Dr. Ronald Thomas for help with statistical analyses.

\section{REFERENCES}

Adachi J, Mizoi Y, Fukunaga T, Ogawa Y, Ueno Y, Imamichi H (1991) Degrees of alcohol intoxication in 117 hospitalized cases. J Stud Alcohol 52:448-453.

Ahlgren SC, Thakur V, Bronner-Fraser M (2002) Sonic hedgehog rescues cranial neural crest from cell death induced by ethanol exposure. Proc Natl Acad Sci USA 99:10476-10481.

Alfonso-Loeches S, Guerri C (2011) Molecular and behavioral aspects of the actions of alcohol on the adult and developing brain. Crit Rev Clin Lab Sci 48:19-47.

van Amerongen R, Berns A (2006) Knockout mouse models to study Wnt signal transduction. Trends Genet 22:678-689.

Anthony B, Zhou FC, Ogawa T, Goodlett CR, Ruiz J (2008) Alcohol exposure alters cell cycle and apoptotic events during early neurulation. Alcohol Alcohol 43:261-273.

Barami K, Hao HN, Lotoczky GA, Diaz FG, Lyman WD (2001) Transplantation of human fetal brain cells into ischemic lesions of adult gerbil hippocampus. J Neurosurg 95:308-315.

Bearer CF, Swick AR, O'Riordan MA, Cheng G (1999) Ethanol inhibits L1mediated neurite outgrowth in postnatal rat cerebellar granule cells. J Biol Chem 274:13264-13270.

Cadigan KM, Nusse R (1997) Wnt signaling: a common theme in animal development. Genes Dev 11:3286-3305.

Camarillo C, Miranda RC (2008) Ethanol exposure during neurogenesis induces persistent effects on neural maturation: evidence from an ex vivo model of fetal cerebral cortical neuroepithelial progenitor maturation. Gene Expr 14:159-171.

Castelo-Branco G, Arenas E (2006) Function of Wnts in dopaminergic neuron development. Neurodegener Dis 3:5-11.

Cerpa W, Toledo EM, Varela-Nallar L, Inestrosa NC (2009) The role of Wnt signaling in neuroprotection. Drug News Perspect 22:579-591.

Charytoniuk D, Porcel B, Rodríguez Gomez J, Faure H, Ruat M, Traiffort E (2002) Sonic Hedgehog signalling in the developing and adult brain. J Physiol Paris 96:9-16.

Chrisman K, Kenney R, Comin J, Thal T, Suchocki L, Yueh YG, Gardner DP (2004) Gestational ethanol exposure disrupts the expression of FGF8 and Sonic hedgehog during limb patterning. Birth Defects Res A Clin Mol Teratol 70:163-171.

Draghici S, Khatri P, Martins RP, Ostermeier GC, Krawetz SA (2003) Global functional profiling of gene expression. Genomics 81:98-104.

Dreosti IE, Ballard FJ, Belling GB, Record IR, Manuel SJ, Hetzel BS (1981) The effect of ethanol and acetaldehyde on DNA synthesis in growing cells and on fetal development in the rat. Alcohol Clin Exp Res 5:357362

Flentke GR, Garic A, Amberger E, Hernandez M, Smith SM (2011) Calciummediated repression of beta-catenin and its transcriptional signaling mediates neural crest cell death in an avian model of fetal alcohol syndrome. Birth Defects Res A Clin Mol Teratol 91:591-602.

Freese JL, Pino D, Pleasure SJ (2010) Wnt signaling in development and disease. Neurobiol Dis 38:148-153.

Goodlett CR, Horn KH (2001) Mechanisms of alcohol-induced damage to the developing nervous system. Alcohol Res Health 25:175-184.

Goodlett CR, Horn KH, Zhou FC (2005) Alcohol teratogenesis: mechanisms of damage and strategies for intervention. Exp Biol Med (Maywood) 230:394 406.

Greco SJ, Rameshwar P (2007) Enhancing effect of IL-1alpha on neurogenesis from adult human mesenchymal stem cells: implication for inflammatory mediators in regenerative medicine. J Immunol 179:3342-3350.

Groeneveld K, te Marvelde JG, van den Beemd MW, Hooijkaas H, van Dongen JJ (1996) Flow cytometric detection of intracellular antigens for immunophenotyping of normal and malignant leukocytes. Leukemia 10:1383-1389. 
Guerri C (1998) Neuroanatomical and neurophysiological mechanisms involved in central nervous system dysfunctions induced by prenatal alcohol exposure. Alcohol Clin Exp Res 22:304-312.

Guerri C, Sáez R, Sancho-Tello M, Martin de Aquilera E, Renau-Piqueras J (1990) Ethanol alters astrocyte development: a study of critical periods using primary cultures. Neurochem Res 15:559-565.

Haegele L, Ingold B, Naumann H, Tabatabai G, Ledermann B, Brandner S (2003) Wnt signalling inhibits neural differentiation of embryonic stem cells by controlling bone morphogenetic protein expression. Mol Cell Neurosci 24:696-708

Hashimoto-Torii K, Kawasawa YI, Kuhn A, Rakic P (2011) Combined transcriptome analysis of fetal human and mouse cerebral cortex exposed to alcohol. Proc Natl Acad Sci USA 108:4212-4217.

Henderson GI, Devi BG, Perez A, Schenker S (1995) In utero ethanol exposure elicits oxidative stress in the rat fetus. Alcohol Clin Exp Res 19:714 720.

Hicks SD, Miller MW (2011) Effects of ethanol on transforming growth factor beta1-dependent and -independent mechanisms of neural stem cell apoptosis. Exp Neurol 229:372-380.

Hockfield S, McKay RD (1985) Identification of major cell classes in the developing mammalian nervous system. J Neurosci 5:3310-3328.

Hu IC, Singh SP, Snyder AK (1995) Effects of ethanol on glucose transporter expression in cultured hippocampal neurons. Alcohol Clin Exp Res 19:1398-1402.

Hur EM, Zhou FQ (2010) GSK3 signalling in neural development. Nat Rev Neurosci 11:539-551.

Ille F, Sommer L (2005) Wnt signaling: multiple functions in neural development. Cell Mol Life Sci 62:1100-1108.

Jones KL (2011) The effects of alcohol on fetal development. Birth Defects Res C Embryo Today 93:3-11.

Jones KL, Smith DW (1973) Recognition of the fetal alcohol syndrome in early infancy. Lancet 2:999-1001.

Jones KL, Smith DW, Hall BD, Hall JG, Ebbin AJ, Massoud H, Golbus MS (1974a) A pattern of craniofacial and limb defects secondary to aberrant tissue bands. J Pediatr 84:90-95.

Jones KL, Smith DW, Streissguth AP, Myrianthopoulos NC (1974b) Outcome in offspring of chronic alcoholic women. Lancet 1:1076-1078.

Jones KL, Smith DW, Ulleland CN, Streissguth P (1973) Pattern of malformation in offspring of chronic alcoholic mothers. Lancet 1:12671271.

Khatri P, Sellamuthu S, Malhotra P, Amin K, Done A, Draghici S (2005) Recent additions and improvements to the Onto-Tools. Nucleic Acids Res 33(Web Server issue):W762-W765.

Kodituwakku PW (2007) Defining the behavioral phenotype in children with fetal alcohol spectrum disorders: a review. Neurosci Biobehav Rev 31:192201.

Kodituwakku PW, May PA, Clericuzio CL, Weers D (2001) Emotion-related learning in individuals prenatally exposed to alcohol: an investigation of the relation between set shifting, extinction of responses, and behavior. Neuropsychologia 39:699-708.

Kotch LE, Chen SY, Sulik KK (1995) Ethanol-induced teratogenesis: free radical damage as a possible mechanism. Teratology 52:128-136.

Kühl M, Sheldahl LC, Park M, Miller JR, Moon RT (2000) The Wnt/Ca2+ pathway: a new vertebrate Wnt signaling pathway takes shape. Trends Genet 16:279-283.

Kuhn P, Sarkar DK (2008) Ethanol induces apoptotic death of beta-endorphin neurons in the rat hypothalamus by a TGF-beta 1-dependent mechanism. Alcohol Clin Exp Res 32:706-714.

Lange C, Mix E, Frahm J, Glass A, Müller J, Schmitt O, Schmöle AC, Klemm K, Ortinau S, Hübner R, Frech MJ, Wree A, Rolfs A (2011) Small molecule GSK-3 inhibitors increase neurogenesis of human neural progenitor cells. Neurosci Lett 488:36-40.

Lee SM, Tole S, Grove E, McMahon AP (2000) A local Wnt-3a signal is required for development of the mammalian hippocampus. Development 127:457-467.

Lendahl U, Zimmerman LB, McKay RD (1990) CNS stem cells express a new class of intermediate filament protein. Cell 60:585-595.
Li YX, Yang HT, Zdanowicz M, Sicklick JK, Qi Y, Camp TJ, Diehl AM (2007) Fetal alcohol exposure impairs Hedgehog cholesterol modification and signaling. Lab Invest 87:231-240.

Lindsley TA, Kerlin AM, Rising LJ (2003) Time-lapse analysis of ethanol's effects on axon growth in vitro. Brain Res Dev Brain Res 147:191-199.

Lindsley TA, Miller MW, Littner Y, Bearer CF (2006) Signaling pathways regulating cell motility: a role in ethanol teratogenicity? Alcohol Clin Exp Res 30:1445-1450.

Lindsley TA, Shah SN, Ruggiero EA (2011) Ethanol alters BDNF-induced Rho GTPase activation in axonal growth cones. Alcohol Clin Exp Res 35:1321-1330.

Liu Y, Chen G, Ma C, Bower KA, Xu M, Fan Z, Shi X, Ke ZJ, Luo J (2009) Overexpression of glycogen synthase kinase 3 beta sensitizes neuronal cells to ethanol toxicity. J Neurosci Res 87:2793-2802.

Loucks EJ, Ahlgren SC (2009) Deciphering the role of Shh signaling in axial defects produced by ethanol exposure. Birth Defects Res A Clin Mol Teratol 85:556-567.

Luo J (2009) GSK3beta in ethanol neurotoxicity. Mol Neurobiol 40:108-121.

Luo J, Miller MW (1999) Transforming growth factor betal-regulated cell proliferation and expression of neural cell adhesion molecule in B104 neuroblastoma cells: differential effects of ethanol. J Neurochem 72:22862293.

Mann LI, Bhakthavathsalan A, Liu M, Makowski P (1975) Effect of alcohol on fetal cerebral function and metabolism. Am J Obstet Gynecol 122:845851.

Mattson SN, Riley EP (1998) A review of the neurobehavioral deficits in children with fetal alcohol syndrome or prenatal exposure to alcohol. Alcohol Clin Exp Res 22:279-294.

Mattson SN, Riley EP, Delis DC, Stern C, Jones KL (1996) Verbal learning and memory in children with fetal alcohol syndrome. Alcohol Clin Exp Res 20:810-816.

McMahon AP, Bradley A (1990) The Wnt-1 (int-1) proto-oncogene is required for development of a large region of the mouse brain. Cell 62:1073-1085

Miller MW (1989) Effects of prenatal exposure to ethanol on neocortical development: II. Cell proliferation in the ventricular and subventricular zones of the rat. J Comp Neurol 287:326-338.

Miller MW, Dow-Edwards DL (1993) Vibrissal stimulation affects glucose utilization in the trigeminal/somatosensory system of normal rats and rats prenatally exposed to ethanol. J Comp Neurol 335:283-284.

Miller MW, Nowakowski RS (1991) Effect of prenatal exposure to ethanol on the cell cycle kinetics and growth fraction in the proliferative zones of fetal rat cerebral cortex. Alcohol Clin Exp Res 15:229-232.

Miñana R, Climent E, Barettino D, Segui JM, Renau-Piqueras J, Guerri C (2000) Alcohol exposure alters the expression pattern of neural cell adhesion molecules during brain development. J Neurochem 75:954-964.

Miñana R, Sancho-Tello M, Climent E, Seguí JM, Renau-Piqueras J, Guerri C (1998) Intracellular location, temporal expression, and polysialylation of neural cell adhesion molecule in astrocytes in primary culture. Glia 24:415427.

Miraglia S, Godfrey W, Yin AH, Atkins K, Warnke R, Holden JT, Bray RA, Waller EK, Buck DW (1997) A novel five-transmembrane hematopoietic stem cell antigen: isolation, characterization, and molecular cloning. Blood 90:5013-5021.

de la Monte SM, Tong M, Bowling N, Moskal P (2011) si-RNA inhibition of brain insulin or insulin-like growth factor receptors causes developmental cerebellar abnormalities: relevance to fetal alcohol spectrum disorder. Mol Brain 4:13.

Neznanova O, Björk K, Rimondini R, Hansson AC, Hyytiä P, Heilig M, Sommer WH (2009) Acute ethanol challenge inhibits glycogen synthase kinase-3beta in the rat prefrontal cortex. Int $\mathbf{J}$ Neuropsychopharmacol 12:275-280.

Parashar S, Reid KJ, Spertus JA, Shaw LJ, Vaccarino V (2010) Early menopause predicts angina after myocardial infarction. Menopause 17:938-945.

Pennington SN, Boyd JW, Kalmus GW, Wilson RW (1983) The molecular mechanism of fetal alcohol syndrome (FAS). I. Ethanol-induced growth suppression. Neurobehav Toxicol Teratol 5:259-262. 
Perper JA, Twerski A, Wienand JW (1986) Tolerance at high blood alcohol concentrations: a study of 110 cases and review of the literature. J Forensic Sci 31:212-221.

Prock TL, Miranda RC (2007) Embryonic cerebral cortical progenitors are resistant to apoptosis, but increase expression of suicide receptor DISCcomplex genes and suppress autophagy following ethanol exposure. Alcohol Clin Exp Res 31:694-703.

Ramanathan R, Wilkemeyer MF, Mittal B, Perides G, Charness ME (1996) Alcohol inhibits cell-cell adhesion mediated by human L1. J Cell Biol 133:381-390.

Rodríguez FD, Simonsson P, Alling C (1992) A method for maintaining constant ethanol concentrations in cell culture media. Alcohol Alcohol 27:309-313.

Sakata-Haga H, Sawada K, Ohta K, Cui C, Hisano S, Fukui Y (2003) Adverse effects of maternal ethanol consumption on development of dorsal hippocampus in rat offspring. Acta Neuropathol (Berl) 105:30-36.

Sathyan P, Golden HB, Miranda RC (2007) Competing interactions between micro-RNAs determine neural progenitor survival and proliferation after ethanol exposure: evidence from an ex vivo model of the fetal cerebral cortical neuroepithelium. J Neurosci 27:8546-8557.

Shibley IA Jr, Pennington SN (1997) Metabolic and mitotic changes associated with the fetal alcohol syndrome. Alcohol Alcohol 32:423-434.

Siegenthaler JA, Miller MW (2004) Transforming growth factor betal modulates cell migration in rat cortex: effects of ethanol. Cereb Cortex 14:791-802.

Singh AK, Gupta S, Jiang Y, Younus M, Ramzan M (2009) In vitro neurogenesis from neural progenitor cells isolated from the hippocampus region of the brain of adult rats exposed to ethanol during early development through their alcohol-drinking mothers. Alcohol Alcohol 44:185-198.

Singh SP, Ehmann S, Snyder AK (1994) Ethanol and glucose-deprivation neurotoxicity in cortical cell cultures. Metabolism 43:1108-1113.

Singh SP, Srivenugopal KS, Yuan XH, Jiang F, Snyder AK (1993) Effects of ethanol ingestion on glucose transporter-1 protein and mRNA levels in rat brain. Life Sci 53:1811-1819.

Smalley MJ, Dale TC (1999) Wnt signalling in mammalian development and cancer. Cancer Metastasis Rev 18:215-230.

Snyder AK, Jiang F, Singh SP (1992a) Effects of ethanol on glucose utilization by cultured mammalian embryos. Alcohol Clin Exp Res 16:466 470.

Snyder AK, Singh SP (1989) Effects of ethanol on glucose turnover in pregnant rats. Metabolism 38:149-152.

Snyder AK, Singh SP, Ehmann S (1992b) Effects of ethanol on DNA, RNA, and protein synthesis in rat astrocyte cultures. Alcohol Clin Exp Res 16:295300 .

Tamaki S, Eckert K, He D, Sutton R, Doshe M, Jain G, Tushinski R, Reitsma M, Harris B, Tsukamoto A, Gage F, Weissman I, Uchida N (2002) Engraftment of sorted/expanded human central nervous system stem cells from fetal brain. J Neurosci Res 69:976-986.

Tang N, He M, O'Riordan MA, Farkas C, Buck K, Lemmon V, Bearer CF (2006) Ethanol inhibits L1 cell adhesion molecule activation of mitogen-activated protein kinases. J Neurochem 96:1480-1490.
Tateno M, Ukai W, Ozawa H, Yamamoto M, Toki S, Ikeda H, Saito T (2004) Ethanol inhibition of neural stem cell differentiation is reduced by neurotrophic factors. Alcohol Clin Exp Res 28(8 Suppl Proceedings):134S $138 \mathrm{~S}$.

Tateno M, Ukai W, Yamamoto M, Hashimoto E, Ikeda H, Saito T (2005) The effect of ethanol on cell fate determination of neural stem cells. Alcohol Clin Exp Res 29(12 Suppl):225S-229S.

Toledo EM, Colombres M, Inestrosa NC (2008) Wnt signaling in neuroprotection and stem cell differentiation. Prog Neurobiol 86:281-296.

Uchida N, Buck DW, He D, Reitsma MJ, Masek M, Phan TV, Tsukamoto AS, Gage FH, Weissman IL (2000) Direct isolation of human central nervous system stem cells. Proc Natl Acad Sci USA 97:14720-14725.

Vangipuram SD, Grever WE, Parker GC, Lyman WD (2008) Ethanol increases fetal human neurosphere size and alters adhesion molecule gene expression. Alcohol Clin Exp Res 32:339-347.

Vangipuram SD, Lyman WD (2010) Ethanol alters cell fate of fetal human brain-derived stem and progenitor cells. Alcohol Clin Exp Res 34:1574 1583.

Vingan RD, Dow-Edwards DL, Riley EP (1986) Cerebral metabolic alterations in rats following prenatal alcohol exposure: a deoxyglucose study. Alcohol Clin Exp Res 10:22-26.

Yamada Y, Nagase T, Nagase M, Koshima I (2005) Gene expression changes of sonic hedgehog signaling cascade in a mouse embryonic model of fetal alcohol syndrome. J Craniofac Surg 16:1055-1061; discussion 1062-1053.

Yi JJ, Barnes AP, Hand R, Polleux F, Ehlers MD (2010) TGF-beta signaling specifies axons during brain development. Cell 142:144-157.

Yu TW, Bargmann CI (2001) Dynamic regulation of axon guidance. Nat Neurosci 4(Suppl):1169-1176.

Zhou FC, Balaraman Y, Teng M, Liu Y, Singh RP, Nephew KP (2011) Alcohol alters DNA methylation patterns and inhibits neural stem cell differentiation. Alcohol Clin Exp Res 35:735-746.

\section{SUPPORTING INFORMATION}

Additional Supporting Information may be found in the online version of this article:

Table S1. List of genes on the array that were absent/ present in samples.

Data S1. References for gene functions in Table 1.

Please note: Wiley-Blackwell is not responsible for the content or functionality of any supporting materials supplied by the authors. Any queries (other than missing material) should be directed to the corresponding author for the article. 